\title{
Role of Reactive Oxygen Species in the Progression of Type 2 Diabetes and Atherosclerosis
}

\author{
Hideaki Kaneto, Naoto Katakami, Munehide Matsuhisa, and Taka-aki Matsuoka \\ Department of Metabolic Medicine, Graduate School of Medicine, Osaka University, 2-2 Yamadaoka, Suita, Osaka 565-0871, Japan \\ Correspondence should be addressed to Hideaki Kaneto, kaneto@endmet.med.osaka-u.ac.jp
}

Received 28 September 2009; Accepted 13 November 2009

Academic Editor: Giamila Fantuzzi

Copyright ( $) 2010$ Hideaki Kaneto et al. This is an open access article distributed under the Creative Commons Attribution License, which permits unrestricted use, distribution, and reproduction in any medium, provided the original work is properly cited.

Type 2 diabetes is the most prevalent and serious metabolic disease all over the world, and its hallmarks are pancreatic $\beta$-cell dysfunction and insulin resistance. Under diabetic conditions, chronic hyperglycemia and subsequent augmentation of reactive oxygen species (ROS) deteriorate $\beta$-cell function and increase insulin resistance which leads to the aggravation of type 2 diabetes. In addition, chronic hyperglycemia and ROS are also involved in the development of atherosclerosis which is often observed under diabetic conditions. Taken together, it is likely that ROS play an important role in the development of type 2 diabetes and atherosclerosis.

\section{Augmentation of Reactive Oxygen Species (ROS) by Various Pathways under Diabetic Conditions}

It has been shown that ROS are produced in various tissues under diabetic conditions $[1,2]$. There are several sources of ROS in cells such as the nonenzymatic glycosylation reaction [3], the electron transport chain in mitochondria [4], and membrane-bound NADPH oxidase $[5,6]$. In diabetic animals, glycation reaction is observed in various tissues and organs, and various kinds of glycated proteins such as glycosylated hemoglobin, albumin, and lens crystalline are produced in a nonenzymatical manner through the glycation reaction. The reaction produces Schiff base, Amadori product, and finally advanced glycosylation end products (AGEs). During the process, ROS are also produced. The electron transport chain in mitochondria is also an important pathway to produce ROS. Under diabetic conditions, electron transport chain is activated, which leads to production of larger amounts of ROS. It has been shown that membranebound NADPH oxidase is also an important source of ROS. NADPH oxidase is composed of the membrane-bound subunits gp91 phox (Nox2)/Nox1/Nox4 and p22 phox and the catalytic site of the oxidase and cytosolic components 47 phox and p67 phox. NADPH oxidase is activated by various stimuli such as AGEs, insulin, and angiotensin II; all of which are possibly induced under diabetic conditions (Figures 1(a) and $1(b))$.

\section{Role of ROS in the Progression of Pancreatic $\beta$-Cell Dysfunction in Type 2 Diabetes}

Acute exposure of $\beta$-cells to a high glucose concentration stimulates insulin gene expression, but chronic exposure has various adverse effects on various $\beta$-cell function. However, chronic hyperglycemia is a cause of impairment of insulin biosynthesis and secretion. This process is called $\beta$-cell glucose toxicity which is often observed under diabetic conditions. In the diabetic state, hyperglycemia per se and subsequent production of ROS decrease insulin gene expression and secretion and finally bring about apoptosis [7-28]. It has been shown that the loss of insulin gene expression is accompanied by decreased expression and/or DNA binding activities of transcription factors: pancreatic and duodenal homeobox-1 (PDX-1) [19-26] and MafA [10, 12, 15]. After chronic exposure to a high glucose concentration, expression and/or DNA binding activities of these two transcription factors are reduced. It is noted here that PDX-1 plays a crucial role in pancreas development, $\beta$-cell differentiation, induction of surrogate $\beta$-cells, and maintenance of mature 


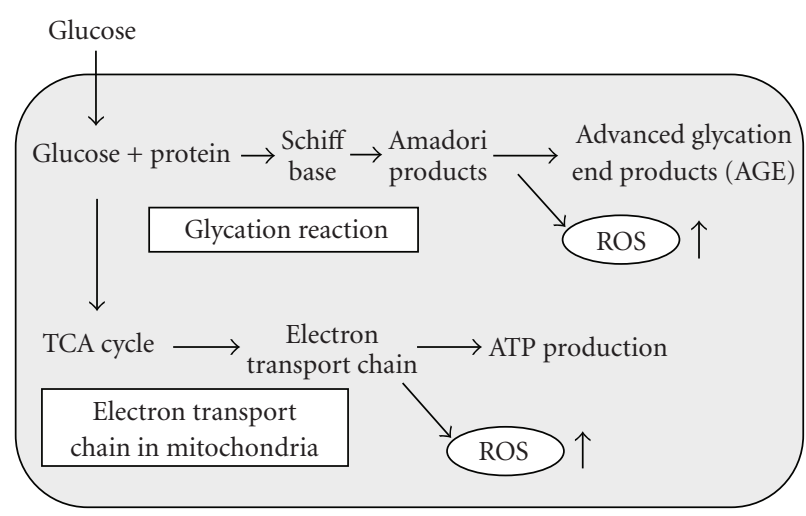

(a)

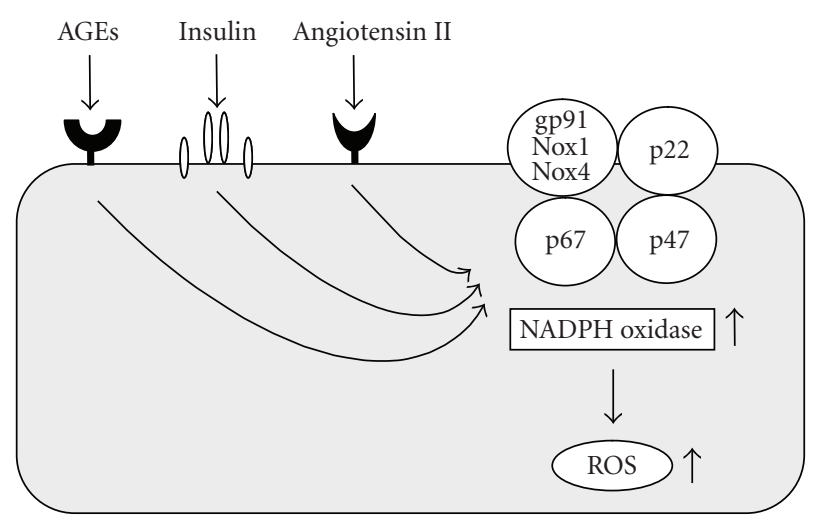

(b)

FIGURE 1: Augmentation of ROS by various pathways under diabetic conditions. (a) ROS are produced by various pathways under diabetic conditions. Hyperglycemia induces ROS through activation of the glycation reaction and electron transport chain in mitochondria. (b) AGEs, insulin, and angiotensin II induces ROS through activation of membrane-bound NADPH oxidase.

$\beta$-cell function [29-41] and that MafA is a recently isolated $\beta$-cell-specific transcription factor and functions as a potent activator of insulin gene transcription [42-47].

Under diabetic conditions, ROS are induced and involved in the $\beta$-cell glucose toxicity [22-36]. $\beta$-Cells express GLUT2, a high-Km glucose transporter, and thereby display highly efficient glucose uptake when exposed to a high glucose concentration. Indeed, it was shown that expressions of ROS markers 8-hydroxy-2'-deoxyguanosine (8-OHdG) and 4-hydroxy-2, 3-nonenal (4-HNE) were increased in islets under diabetic conditions $[14,16]$. In addition, $\beta$-cells are rather vulnerable to ROS due to the relatively low expression of antioxidant enzymes such as catalase and glutathione peroxidase $[48,49]$. Therefore, it is likely that ROS are involved in $\beta$-cell deterioration found in diabetes. It was shown that when $\beta$-cell-derived cell lines or rat isolated islets were exposed to ROS, insulin gene promoter activity and mRNA expression were suppressed [19-26]. In addition, when they were exposed to ROS, binding of PDX-1 and/or MafA to the insulin gene promoter was markedly reduced. Furthermore, it was shown that the decrease of insulin gene expression after chronic exposure to a high glucose concentration was prevented by treatment with antioxidants $[16,19,25,26]$. Reduction of expression and/or DNA binding activities of PDX-1 and MafA by chronic exposure to high glucose was also prevented by an antioxidant treatment. These results suggest that chronic hyperglycemia suppresses insulin biosynthesis and secretion by increasing ROS, accompanied by reduction of expression and/or DNA binding activities of two important pancreatic transcription factors: PDX-1 and MafA. Therefore, it is likely that the alteration of such transcription factors explains, at least in part, the suppression of insulin biosynthesis and secretion, and thus are involved in $\beta$-cell glucose toxicity. Indeed, it was shown that the antioxidant treatment with $\mathrm{N}$-acetyl-L-cysteine plus vitamin $\mathrm{C}$ and $\mathrm{E}$ retained glucosestimulated insulin secretion and moderately ameliorated glucose tolerance in obese diabetic C57BL/KsJ-db/db mice [19]. $\beta$-Cell mass was significantly larger in the mice treated with the antioxidants, and insulin content was preserved by the antioxidant treatment. Furthermore, PDX-1 expression was more clearly visible in the nuclei of $\beta$-cells after the antioxidant treatment [19]. Similar effects were observed with Zucker diabetic fatty rats, another model animal for type 2 diabetes [25]. Therefore, it is likely that antioxidant treatment can protect $\beta$-cells against glucose toxicity. In addition, angiotensin II type 1 receptor blocker (ARB) has antioxidant effects and thereby treatment with $A R B$ exerts beneficial effects for diabetes [50, 51]. Indeed, it was shown that when diabetic $\mathrm{C} 57 \mathrm{BL} / \mathrm{KsJ}-\mathrm{db} / \mathrm{db}$ mice were treated with $\mathrm{ARB}, \beta$-cell mass and insulin content were increased, and expressions of components of $\mathrm{NAD}(\mathrm{P}) \mathrm{H}$ oxidase and ROS markers in $\beta$-cells were decreased. The ARB treatment also reduced fibrosis in and around the islets and prevented the loss of endothelial cells in islets. These results suggest that ARB treatment protects $\beta$-cells by reducing ROS and further strengthen the hypothesis that ROS are involved in $\beta$-cell glucose toxicity found in diabetes.

It is known that lipotoxicity is also involved in the deterioration of $\beta$-cell function found in type 2 diabetes. When islets or $\beta$-cell-derived cell lines were exposed to free fatty acids (FFAs), ROS were induced, which led to the reduction of insulin secretion and $\beta$-cell dysfunction [5256]. It was also reported that FFA-mediated induction of inducible nitric oxide synthase (iNOS) and excess nitric oxide (NO) generation were involved in the progression of $\beta$-cell dysfunction [57]. Because intracellular NO is an important mediator of $\beta$-cell apoptosis [58], it is likely that the loss of $\beta$-cell mass observed in type 2 diabetes is due to NO-induced apoptosis.

It has been suggested that activation of the c-Jun $\mathrm{N}$ terminal kinase (JNK) pathway is involved in pancreatic $\beta$ cell dysfunction found in type 2 diabetes. It was reported that activation of the JNK pathway is involved in reduction of insulin gene expression by ROS and that suppression of the JNK pathway can protect $\beta$-cells from ROS [59]. When isolated rat islets were exposed to ROS, the JNK pathway was activated, preceding the decrease of insulin gene expression. Adenoviral overexpression of dominant-negative type JNK1 (DN-JNK) protected insulin gene expression and secretion from ROS. These results were correlated with 


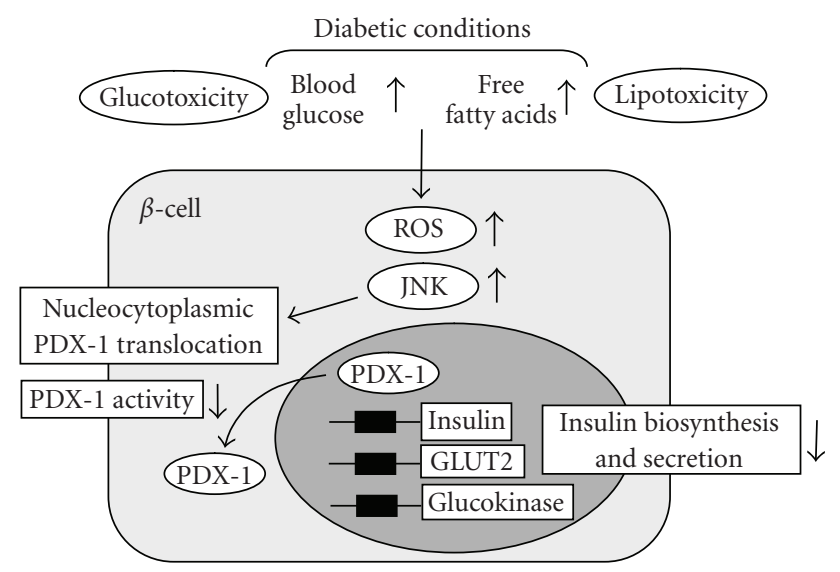

FIgURE 2: Role of ROS in the progression of pancreatic $\beta$-cell dysfunction in type 2 diabetes. ROS are provoked by hyperglycemia and/or hyperlipidemia under diabetic conditions, which leads to activation of the JNK pathway in pancreatic $\beta$-cells. ROS and subsequent activation of the JNK pathway induce nucleocytoplasmic translocation of PDX-1, which leads to reduction of PDX-1 activity and suppression of insulin. Therefore, it is likely that ROS and activation of the JNK pathway are involved in $\beta$-cell dysfunction found in type 2 diabetes.

change in the binding of PDX-1 to the insulin promoter. Adenoviral overexpression of DN-JNK preserved PDX-1 DNA binding activity in the face of ROS, while WTJNK overexpression decreased PDX-1 DNA binding activity [59]. Taken together, it is likely that activation of the JNK pathway leads to decreased PDX-1 activity and consequent suppression of insulin gene transcription found in the diabetic state. Also, it was shown that PDX-1 is translocated from the nuclei to the cytoplasm in response to ROS. When $\beta$-cell-derived HIT cells were exposed to ROS, both intrinsically expressed PDX-1 and exogenously introduced green fluorescent protein (GFP)-tagged PDX-1 moved from the nuclei to the cytoplasm [60]. DN-JNK overexpression inhibited the ROS-induced PDX-1 translocation, suggesting that activation of the JNK pathway is involved in PDX-1 translocation by ROS. Furthermore, leptomycin B, a specific inhibitor of the classical, leucine-rich nuclear export signal (NES), inhibited nucleo-cytoplasmic translocation of PDX1 induced by ROS [60]. Taken together, it is likely that ROS induce nucleo-cytoplasmic translocation of PDX-1 through activation of the JNK pathway, which leads to reduction of its DNA binding activity and suppression of insulin biosynthesis (Figure 2).

The forkhead transcription factor Foxol is known as one of the important fundamental transcription factors playing a key role in apoptosis, cellular proliferation and differentiation, and glucose metabolism through regulating the transcription of various target genes $[61,62]$. It was shown that Foxol regulates hepatic gluconeogenesis, and thus contributes to insulin resistance [63]. Insulin inhibits the function of Foxol through Akt/PKB-mediated phosphorylation and nuclear exclusion [64], and thereby suppresses hepatic gluconeogenesis. It was also shown that Foxol exhibits a counter localization to PDX-1 in $\beta$-cells [65], suggesting that it is involved in the deterioration of $\beta$-cell function. Moreover, it was shown that Foxol plays a role as a mediator between the JNK pathway and PDX-1 [66]. In $\beta$-cell-derived cell line HIT-T15, Foxo 1 changed its intracellular localization from the cytoplasm to the nucleus after exposure to ROS. In contrast to Foxo1, the nuclear expression of PDX-1 was decreased and its cytoplasmic distribution was increased by ROS. Activation of the JNK pathway also induced the nuclear localization of Foxo1, whereas suppression of the JNK pathway reduced the ROS-induced nuclear localization of Foxo1, suggesting an involvement of the JNK pathway in Foxo1 translocation [66]. In addition, ROS or activation of the JNK pathway decreased Akt phosphorylation in HIT cells, leading to the decreased phosphorylation of Foxol following nuclear localization. Furthermore, adenoviral Foxo1 overexpression reduced the nuclear expression of PDX1, whereas suppression of Foxo1 by Foxol-specific small interfering RNA retained the nuclear expression of PDX1 [66]. Taken together, ROS and subsequent activation of the JNK pathway induce nuclear translocation of Foxo1 through the modification of the insulin signaling in $\beta$-cells, which leads to the nucleo-cytoplasmic translocation of PDX1 and reduction of its DNA binding activity. It was also shown that the mammalian Ste20-like kinase 1 (MST1) is activated by ROS, which facilitates Foxo1 translocation from the cytoplasm to the nuclei [67]. Therefore, it is also possible that ROS trigger Foxol translocation from the cytoplasm to the nuclei, independently of Akt activity or Aktmediated phosphorylation status of Foxo1. Furthermore, the significance of the JNK pathway in the development of diabetes comes from the result of a genetic analysis in humans. While islet-brain-1 (IB1) was known to suppress the JNK pathway $[68,69]$, it was shown that a missense mutation within the IB1-encoding MAPKIP1 gene (S59N) is associated with a late onset type 2 diabetes [70]. Thus, it is likely that activation of the JNK pathway is involved in deterioration of $\beta$-cell function found in type 2 diabetes.

\section{Role of ROS in the Progression of Insulin Resistance in Type 2 Diabetes}

The hallmark of type 2 diabetes is insulin resistance as well as pancreatic $\beta$-cell dysfunction. Under diabetic conditions, various insulin target tissues such as the liver, muscle, and fat become resistant to insulin. The pathophysiology of insulin resistance involves a complex network of insulin signaling pathways. After insulin binds to insulin receptor on cell surface, insulin receptor and its substrates are phosphorylated, which leads to activation of various insulin signaling pathways [71-74]. It has been shown that ROS are involved in the progression of insulin resistance as well as pancreatic $\beta$-cell dysfunction [75]. Indeed, it was previously reported that ROS disrupted insulin-induced cellular redistribution of insulin receptor substrate-1 (IRS-1) and phosphatidylinositol 3-kinase (PI 3-K), and thus impaired insulin-induced GLUT4 translocation in 3T3-L1 adipocyte [76, 77]. It was also reported that treatment with antioxidants ( $\mathrm{N}$-acetylL-cysteine and taurine) prevented hyperglycemia-induced insulin resistance in vivo [78]. Furthermore, in patients with 
type 2 diabetes, both acute and chronic administrations of $\alpha$-lipoic acid, an antioxidant, improved insulin resistance, suggesting that ROS are involved in the progression of insulin resistance $[79,80]$.

Under diabetic conditions, hyperglycemia increased ROS, which presumably lead to activation of the JNK pathway. In addition, under diabetic conditions, free fatty acids (FFAs), various inflammatory cytokines (e.g., TNF $\alpha$ ), and endoplasmic reticulum (ER) stress are increased, which also leads to activation of the JNK pathway. Finally, it has been suggested that activation of the JNK pathway is involved in insulin resistance as well as pancreatic $\beta$-cell dysfunction found in diabetes $[81,82]$. It was reported that the JNK pathway was abnormally activated in the liver, muscle, and adipose tissue in obese type 2 diabetic mice and that insulin resistance in obese type 2 diabetic mice was substantially reduced in mice homozygous for a targeted mutation in the JNK1 gene (JNK-KO mice) [83]. When the JNK-KO and control mice were placed on a high-fat/high-caloric diet, blood glucose levels in the obese JNK-KO mice were significantly lower compared to obese wild-type mice. Intraperitoneal insulin tolerance tests showed that hypoglycemic response to insulin in obese wildtype mice was lower compared to obese JNK-KO mice. Also, intraperitoneal glucose tolerance test revealed a higher degree of hyperglycemia in obese wild-type mice than obese JNK-KO mice. These results indicate that the JNK-KO mice are protected from the development of dietary obesityinduced insulin resistance. Furthermore, targeted mutations in JNK1 were introduced in genetically obese mice (ob/ob) [83]. Blood glucose levels in the ob/ob-JNK-KO mice were lower compared to ob/ob wild-type mice, and the ob/ob wild-type mice displayed a severe and progressive hyperinsulinemia. Therefore, it is likely that JNK1 deficiency provides resistance against obesity, hyperglycemia, and hyperinsulinemia in both genetic and dietary models of diabetes. These results suggest that activation of the JNK pathway plays an important role in the development of insulin resistance found in type 2 diabetes. It was also reported that overexpression of dominant-negative (DN) type JNK1 (AdDN-JNK) in the liver of obese diabetic C57BL/KsJ-db/db mice improved insulin resistance and ameliorated glucose intolerance [83]. In intraperitoneal insulin tolerance test, the hypoglycemic response to insulin was larger in Ad-DNJNK-treated $\mathrm{db} / \mathrm{db}$ mice. Furthermore, in the euglycemic hyperinsulinemic clamp test, glucose infusion rate (GIR) in Ad-DN-JNK-treated mice was higher than that in AdGFP-treated mice, indicating that suppression of the JNK pathway in the liver reduces insulin resistance, and thus ameliorates glucose intolerance in the $\mathrm{db} / \mathrm{db}$ mice. Furthermore, hepatic glucose production (HGP) was significantly lower in Ad-DN-JNK-treated mice, whereas there was no difference in the glucose disappearance rate $(\mathrm{Rd})$ between these two groups [84]. These results indicate that reduction of insulin resistance and amelioration of glucose tolerance by DN-JNK overexpression are mainly due to suppression of hepatic glucose production. It has been reported that serine phosphorylation of insulin receptor substrate-1 (IRS1) inhibits insulin-stimulated tyrosine phosphorylation of

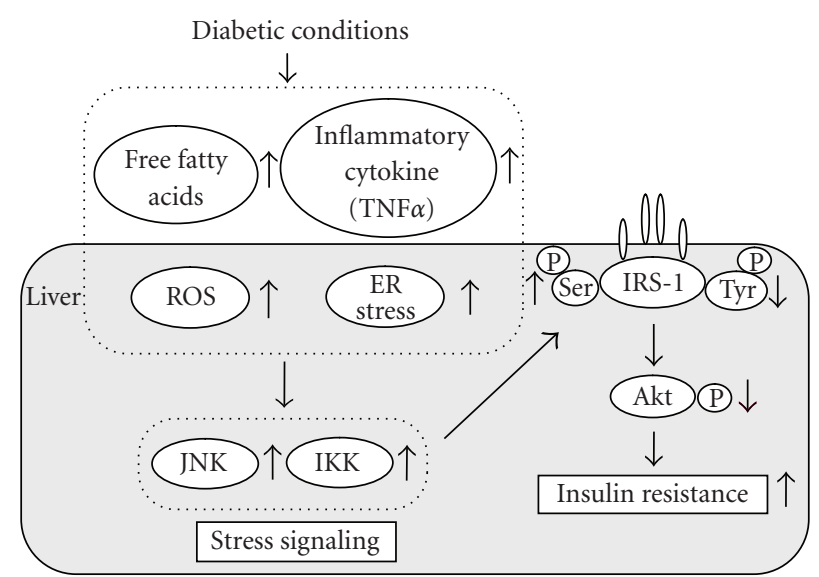

FIGURE 3: Role of ROS in the development of insulin resistance in type 2 diabetes. The JNK pathway is activated by various factors such as ROS, ER stress, free fatty acids (FFAs), and inflammatory cytokines such as TNF $\alpha$ and is involved in the development of insulin resistance found in type 2 diabetes. It has been also shown that the IkappaB kinase $\beta$ (IKK) pathway is also activated by such factors and is involved in the development of insulin resistance. Therefore, it is likely that activation of stress signaling is involved in the development of insulin resistance.

IRS-1, leading to an increase in insulin resistance [85]. IRS-1 serine 307 phosphorylation was decreased and IRS-1 tyrosine phosphorylation was increased in Ad-DN-JNK-treated mice [84]. Therefore, it is likely that an increase in IRS-1 serine phosphorylation is associated with the development of insulin resistance induced by JNK overexpression. Taken together, suppression of the JNK pathway enhances insulin signaling which leads to amelioration of glucose tolerance (Figure 3).

Protein transduction domains (PTDs) such as the small PTD from the TAT protein of human immunodeficiency virus (HIV-1), the VP22 protein of Herpes simplex virus, and the third $\alpha$-helix of the homeodomain of Antennapedia, a Drosophila transcription factor, are known to allow various proteins and peptides to be efficiently delivered into cells through the plasma membrane, and thus there has been increasing interest in their potential usefulness for the delivery of bioactive proteins and peptides into cells [8691]. It was reported that the cell permeable JNK inhibitory peptide is effective for the treatment of diabetes. This peptide is derived from the JNK binding domain of JNK-interacting protein-1 (JIP-1) and has been reported to function as a dominant inhibitor of the JNK pathway [92]. It is noted here that JIP-1 itself is a scaffold protein which binds JNK and activates the JNK pathway. When this peptide was injected intraperitoneally to $\mathrm{C} 57 \mathrm{BL} / \mathrm{Ks}$ - $\mathrm{db} / \mathrm{db}$ obese diabetic mice, the FITC-conjugated peptide showed fluorescence signals in insulin target organs (liver, fat, and muscle) and in insulin secreting tissue (pancreatic islets) [93]. In insulin tolerance test, reduction of blood glucose levels in response to injected insulin was larger in JNK inhibitory peptide-treated mice [93]. Furthermore, in the euglycemic hyperinsulinemic clamp test, the steady-state glucose infusion rate (GIR) in 
JNK inhibitory peptide-treated mice was higher than that in untreated mice, indicating that JNK inhibitory peptide reduces insulin resistance in the $\mathrm{db} / \mathrm{db}$ mice. Endogenous hepatic glucose production (HGP) and glucose disappearance rate $(\mathrm{Rd})$ in the JNK inhibitory peptide-treated mice were also evaluated. It is noted that $\mathrm{Rd}$ reflects glucose utilization in the peripheral tissues. HGP in JNK inhibitory peptide-treated mice was lower than that in untreated mice. In addition, Rd in JNK inhibitory peptide-treated mice was higher than that in untreated mice [93]. These results indicate that JNK inhibitory peptide treatment reduces insulin resistance through decreasing HGP and increasing Rd. IRS- 1 serine 307 phosphorylation was decreased and IRS-1 tyrosine phosphorylation was increased in the peptidetreated mice. Concomitantly, glucose intolerance was also ameliorated in JNK inhibitory peptide-treated mice. Taken together, suppression of the JNK pathway improves insulin resistance and ameliorates glucose intolerance, which further strengthens the significance of the JNK pathway in the development of insulin resistance.

The JNK pathway is activated by various factors including ROS, ER stress, FFAs, and inflammatory cytokines such as $\mathrm{TNF} \alpha$ and is involved in the development of insulin resistance found in type 2 diabetes [94-96]. It has been shown the IkappaB kinase $\beta$ (IKK) pathway is also activated by such factors and is involved in the development of insulin resistance [97-100]. Activation of the IKK pathway increases IRS-1 serine phosphorylation which leads to suppression of insulin signaling. Also, suppression of the IKK pathway decreases insulin resistance and ameliorates glucose intolerance in diabetic mice. Therefore, it is likely that activation of stress signaling such as the JNK and IKK pathways is involved in the development of insulin resistance and that such pathways could be a therapeutic target for diabetes (Figure 3).

\section{Role of ROS in the Progression of Atherosclerosis}

Atherosclerosis is often observed as a macroangiopathy under diabetic conditions. Indeed, it has been reported that increase of intima-media thickness (IMT) in carotid artery, an index of the progression of atherosclerosis, is often observed in diabetic patients [101-103] and that the progression of IMT is influenced by a variety of genetic risk factors [104-106] and/or intervention for diabetes [107109]. It is well known that hyperglycemia per se found under diabetic conditions facilitates the progression of atherosclerosis. In addition, hyperinsulinemia which is often observed in subjects with insulin resistance is likely involved in the progression of atherosclerosis.

It has been shown that ROS are induced in endothelial cells under diabetic conditions. There are several sources of reactive oxygen species (ROS) in cells such as the nonenzymatic glycosylation reaction, the electron transport chain in mitochondria, and membrane-bound NADPH oxidase (Figure 4). It has been shown that membrane-bound $\mathrm{NADPH}$ oxidase is the one of the major sources of ROS in the vasculature and that NADPH oxidase-derived ROS play

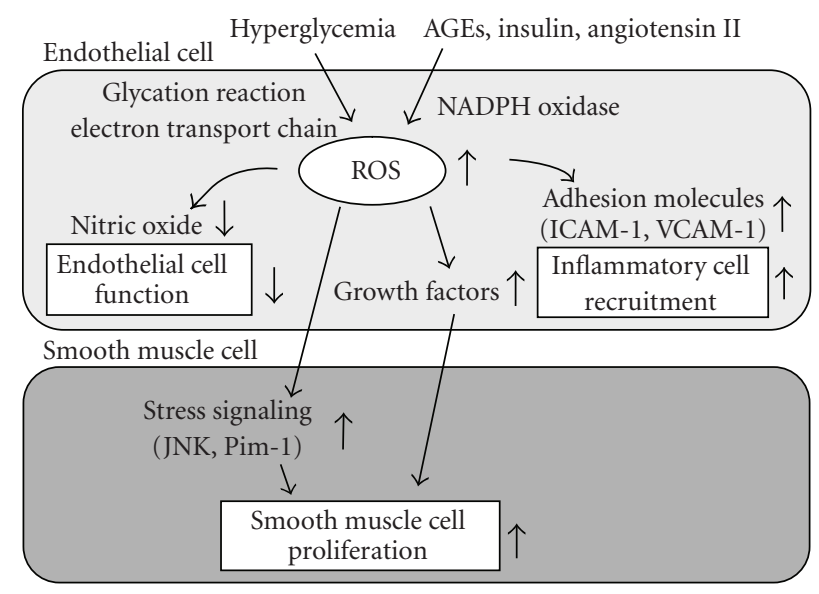

FIgURE 4: Role of ROS in the development of atherosclerosis. ROS are produced by various pathways under diabetic conditions and involved in the development of atherosclerosis in various aspects. Hyperglycemia induces ROS through activation of the glycation reaction and electron transport chain in mitochondria. Also, AGEs, insulin, and angiotensin II induce ROS through activation of NADPH oxidase. Increased ROS are involved in the development of atherosclerosis in various aspects. First, ROS decrease nitric oxide levels, which leads to endothelial cell dysfunction. Second, ROS increase expression of various adhesion molecules such as ICAM1 and VCAM-1, which leads to inflammatory cell recruitment. Finally, ROS increase expression of various growth factors and activate various stress signaling such as JNK and Pim-1, which leads to proliferation of smooth muscle cell.

a critical role in the development of atherosclerosis. NADPH oxidase is composed of the membrane-bound subunits gp91 phox (Nox2)/Nox1/Nox4 and p22 phox, and the catalytic site of the oxidase and cytosolic components 477 phox and p67 phox. In vascular cells such as endothelial and smooth muscle cells, Nox 1 and Nox 4, rather than gp91 phox, are abundantly expressed. NADPH oxidase is activated by various factors such as AGEs, insulin, and angiotensin II; all of which are possibly induced under diabetic conditions [110]. In addition, it was shown that high glucose stimulates ROS production through the activation of NADPH oxidase $[111,112]$ and that the $\mathrm{p} 22$ phox was significantly increased in rat and human diabetic arteries $[113,114]$. Therefore, it is possible that such increased expression of p22 phox contributes to the development of atherosclerosis. It was also reported that mice lacking $\mathrm{p} 47$ phox, which is an important component for NADPH oxidase, had lower levels of aortic ROS production compared with wild-type mice and that when the mice were crossed with apolipoprotein E knockout (p47 phox $(-/-)$, apoE $(-/-)$ ) mice they had significantly fewer lesions in their descending aortas compared to $\mathrm{p} 47$ phox $(+/+)$, apoE $(-/-)$ mice [115]. NADPH oxidasederived ROS play a crucial role in the development of atherosclerosis in human as well as in mice. Indeed, it has been reported that ROS production in atherosclerotic human coronary arteries is associated with NADPH oxidase subunit p22 phox [116]. Also, it has been reported recently that phagocytic NADPH oxidase overactivity is involved in ROS 
and atherosclerosis in metabolic syndrome patients and that hyperinsulinemia likely contributes to ROS in metabolic syndrome patients through activation of NADPH oxidase [117].

In addition, it is likely that the vulnerability to oxidative stress is determined by genetic background. There are several enzymes regulating redox status and the vulnerability to oxidative stress is affected by genetic polymorphisms in these enzymes. For example, it was reported that in type 2 diabetic subjects the C242T polymorphism of the p22 phox gene, an essential component of NADPH oxidase in the vasculature, was closely associated with intima-media thickness (IMT) of the carotid artery, an index of the progression of atherosclerosis [105]. It is noted here that the presence of $242 \mathrm{~T}$ allele is known to be associated with significantly reduced vascular NADPH oxidase activity. Average IMT in the diabetic subjects with the CC genotype was significantly higher compared to those with the TC + TT genotypes. Furthermore, in stepwise multiple regression analysis, p22 phox CC genotype was an independent risk factor for increased IMT in the diabetic subjects [105]. These results suggest that the vulnerability to oxidative stress and the progression of atherosclerosis are influenced by genetic background. Furthermore, the accumulation of oxidative stress-associated gene polymorphisms is likely associated with the severity and the progression of atherosclerosis in diabetic patients. For example, it was reported that carotid intima-media thickness (IMT) as well as serum 8-OHdG level, a marker of oxidative stress, were closely associated with the accumulation of several oxidative stress-associated gene polymorphisms, such as the $\mathrm{T}$ allele of the C-588T polymorphism in glutamate-cysteine ligase modifier subunit (GCLM) gene, the GG genotype of the G-463A polymorphism in myeloperoxidase (MPO) gene, the substitution of Gln for Arg at position 192 in human paraoxonase (PON1), and the $\mathrm{T}$ allele of the $\mathrm{C} 242 \mathrm{~T}$ polymorphism in $\mathrm{NAD}(\mathrm{P}) \mathrm{H}$ oxidase 222 phox gene [118]. Furthermore, the accumulation of these 4-gene polymorphisms was closely associated with the progression of carotid IMT in the longitudinal settings. In a stepwise multivariate regression analysis, the number of prooxidant alleles was an independent risk factor for the progression of IMT [119]. These results further support the hypothesis that the vulnerability to oxidative stress and the progression of atherosclerosis are influenced by genetic background. Furthermore, it was reported that the prevalence of myocardial infarction was significantly higher in the subjects with higher number of prooxidant alleles of these 4 gene polymorphisms [120]. Therefore, it is likely that the accumulation of oxidative stress-related gene polymorphisms influences the prevalence of myocardial infarction as well as atherosclerosis.

Increased ROS are involved in the development of atherosclerosis in various aspects. First, endothelial dysfunction is an early key event in atherosclerosis [121-123]. It has been thought that ROS are involved in the progression of endothelial cell dysfunction, which is accompanied by inactivation of endothelial nitric oxide synthase (eNOS) and decrease of nitric oxide (NO) levels [124]. Second, ROS also induce expression of adhesion molecules such as intercellular adhesion molecule-1 (ICAM-1) and vascular adhesion molecule-1 (VCAM-1), which facilitates inflammatory cell recruitment and lipid deposition in the intimal layer. The subsequent ingestion of excess oxidized low density lipoprotein (LDL) particles by macrophages and monocytes leads to release of various inflammatory cytokines and growth factors. Finally, proliferation of vascular smooth muscle cells (VSMCs) is a key step in the development of atherosclerosis. It has been suggested that ROS regulate expression of various growth factors and several growthrelated protooncogenes such as c-Myc, c-Fos and c-Jun [124, 125]. Clinical mass studies have also provided support for the significance of ROS in the development of atherosclerosis $[126,127]$. Taken together, it is likely that ROS are involved in the VSMC proliferation and development of atherosclerosis through various pathways (Figure 4).

The JNK pathway is known to be activated by ROS in VSMC [128], and activation of the JNK pathway is likely involved in the progression of atherosclerosis. It is known that the JNK pathway plays an important role in the initiation of cellular responses, including cellular gene expression, growth, migration, or apoptosis. It has been previously reported that the JNK pathway is activated in balloon-injured arteries as well [129-131]. In vivo transfection of DNJNK significantly suppressed activation of the JNK pathway and reduced VSMC proliferation in a balloon-injury model [132]. Neointimal formation after balloon-injury was also prevented by DN-JNK overexpression. Bromodeoxyuridine labeling index and total cell-counting analysis showed that DN-JNK remarkably suppressed VSMC proliferation in both the intima and the media after injury. In contrast, gene transfer of wild-type JNK (WT-JNK) significantly enhanced neointimal hyperplasia after balloon-injury. Taken together, activation of the JNK pathway triggers VSMC proliferation, leading to neointimal formation, and the JNK pathway could be a therapeutic target for atherosclerosis. The role of JNK in atherosclerotic plaque formation in vivo was also examined using atherosclerosis-prone apolipoprotein $\mathrm{E}$ knockout mice (ApoE (-/-) mice). Activation of the JNK pathway was closely correlated with the presence of clearly established plaques in ApoE $(-/-)$ mice with a high-cholesterol diet. It was recently reported that atherosclerosis-prone ApoE $(-/-)$ mice simultaneously lacking JNK2 (ApoE $(-/-)$, JNK2 (-/-) mice) developed less atherosclerosis compared to ApoE (-/-) mice [133]. Pharmacological inhibition of the JNK activity also efficiently reduced plaque formation [134]. Macrophages lacking JNK2 displayed suppressed foam cell formation caused by defective uptake and degradation of modified lipoproteins and showed increased amounts of the modified lipoprotein-binding and -internalizing scavenger receptor A (SR-A). Macrophage-restricted deletion of JNK2 was sufficient to decrease atherogenesis [133]. These data suggest that JNK2-dependent phosphorylation of SR-A promotes uptake of lipids in macrophages, and thereby regulates foam cell formation. These results strengthen the significance of the JNK pathway in the progression of atherosclerosis. Furthermore, it was shown that Pim-1, a protooncogene that encodes a serine/threonine kinase, is also induced by ROS, and thus is likely involved in the progression of atherosclerosis $[135,136]$. Pim- 1 was substantially induced in neointimal 
VSMC of balloon injured rat carotid arteries, and in vivo infection with a dominant-negative Pim-1-expressing adenovirus (Ad-DN-Pim-1) markedly suppressed neointima formation and cell cycle progression in the balloon injured arteries [135]. In cultured VSMC, ROS-stimulated cell cycle progression and DNA synthesis were suppressed by DNPim-1 overexpression. Furthermore, Pim-1-producing cells were observed predominantly in the thickened intima of human thoratic aortas and coronary arteries [135]. These findings suggest that ROS and consequent induction of Pim1 expression also play an important role in the progression of atherosclerosis. Taken together, ROS and subsequent activation of various stress signaling such as JNK and Pim-1 are involved in the progression of atherosclerosis (Figure 4).

\section{Conclusion}

ROS are induced under diabetic conditions, which are possibly involved in the progression of pancreatic $\beta$-cell dysfunction and insulin resistance found in type 2 diabetes. Suppression of ROS in obese type 2 diabetic mice restores $\beta$ cell function and insulin sensitivity, leading to amelioration of glucose intolerance. In addition, ROS are involved in the progression of atherosclerosis which is often observed as a macroangiopathy under diabetic conditions. Taken together, it is likely that ROS are closely associated with the development of type 2 diabetes and atherosclerosis. Although at present several clinical trials with antioxidants show only a little effect, if any, on the progression of type 2 diabetes, we think that future therapy with stronger and more appropriate antioxidants would exert some beneficial effects on the development of type 2 diabetes and atherosclerosis.

\section{References}

[1] J. W. Baynes and S. R. Thorpe, "Role of oxidative stress in diabetic complications: a new perspective on an old paradigm,” Diabetes, vol. 48, no. 1, pp. 1-9, 1999.

[2] P. Dandona, K. Thusu, S. Cook, et al., "Oxidative damage to DNA in diabetes mellitus," The Lancet, vol. 347, no. 8999, pp. 444-445, 1996.

[3] T. Sakurai and S. Tsuchiya, "Superoxide production from nonenzymatically glycated protein," FEBS Letters, vol. 236, no. 2, pp. 406-410, 1988.

[4] M. Brownlee, "Biochemistry and molecular cell biology of diabetic complications," Nature, vol. 414, no. 6865, pp. 813 820, 2001.

[5] D. Harrison, K. K. Griendling, U. Landmesser, B. Hornig, and H. Drexler, "Role of oxidative stress in atherosclerosis," The American Journal of Cardiology, vol. 91, no. 3, pp. 7A-11A, 2003.

[6] H. K. M. Mohazzab, P. M. Kaminski, and M. S. Wolin, "NADH oxidoreductase is a major source of superoxide anion in bovine coronary artery endothelium," American Journal of Physiology, vol. 266, no. 6, pp. H2568-H2572, 1994.

[7] G. C. Weir, D. R. Laybutt, H. Kaneto, S. Bonner-Weir, and A. Sharma, " $\beta$-cell adaptation and decompensation during the progression of diabetes," Diabetes, vol. 50, supplement 1, pp. S154-S159, 2001.
[8] M. Prentki and C. J. Nolan, "Islet $\beta$ cell failure in type 2 diabetes," The Journal of Clinical Investigation, vol. 116, no. 7, pp. 1802-1812, 2006.

[9] V. Poitout, L. K. Olson, and R. P. Robertson, "Chronic exposure of $\beta$ TC- 6 cells to supraphysiologic concentrations of glucose decreases binding of the RIPE3b1 insulin gene transcription activator," The Journal of Clinical Investigation, vol. 97, no. 4, pp. 1041-1046, 1996.

[10] V. Poitout and R. P. Robertson, "Minireview: secondary $\beta$ cell failure in type 2 diabetes-a convergence of glucotoxicity and lipotoxicity," Endocrinology, vol. 143, no. 2, pp. 339-342, 2002.

[11] A. Sharma, D. Fusco-DeMane, E. Henderson, S. Efrat, and R. Stein, "The role of the insulin control element and RIPE3b1 activators in glucose-stimulated transcription of the insulin gene," Molecular Endocrinology, vol. 9, no. 11, pp. 1468-1476, 1995.

[12] A. Moran, H.-J. Zhang, L. K. Olson, J. S. Harmon, V. Poitout, and R. P. Robertson, "Differentiation of glucose toxicity from beta cell exhaustion during the evolution of defective insulin gene expression in the pancreatic islet cell line, HIT-T15," The Journal of Clinical Investigation, vol. 99, no. 3, pp. 534-539, 1997.

[13] J. L. Evans, I. D. Goldfine, B. A. Maddux, and G. M. Grodsky, "Are oxidative stress-activated signaling pathways mediators of insulin resistance and $\beta$-cell dysfunction?" Diabetes, vol. 52, pp. 1-8, 2003.

[14] S.-I. Gorogawa, Y. Kajimoto, Y. Umayahara, et al., "Probucol preserves pancreatic $\beta$-cell function through reduction of oxidative stress in type 2 diabetes," Diabetes Research and Clinical Practice, vol. 57, no. 1, pp. 1-10, 2002.

[15] J. S. Harmon, R. Stein, and R. P. Robertson, "Oxidative stress-mediated, post-translational loss of MafA protein as a contributing mechanism to loss of insulin gene expression in glucotoxic beta cells," The Journal of Biological Chemistry, vol. 280, no. 12, pp. 11107-11113, 2005.

[16] Y. Ihara, S. Toyokuni, K. Uchida, et al., "Hyperglycemia causes oxidative stress in pancreatic $\beta$-cells of GK rats, a model of type 2 diabetes," Diabetes, vol. 48, no. 4, pp. 927932, 1999.

[17] Y. Kajimoto, T. Matsuoka, H. Kaneto, et al., "Induction of glycation suppresses glucokinase gene expression in HIT-T15 cells," Diabetologia, vol. 42, no. 12, pp. 1417-1424, 1999.

[18] P. Maechler, L. Jornot, and C. B. Wollheim, "Hydrogen peroxide alters mitochondrial activation and insulin secretion in pancreatic beta cells," The Journal of Biological Chemistry, vol. 274, no. 39, pp. 27905-27913, 1999.

[19] H. Kaneto, Y. Kajimoto, J. Miyagawa, et al., "Beneficial effects of antioxidants in diabetes: possible protection of pancreatic $\beta$-cells against glucose toxicity," Diabetes, vol. 48, no. 12, pp. 2398-2406, 1999.

[20] H. Kaneto, G. Xu, K.-H. Song, et al., "Activation of the hexosamine pathway leads to deterioration of pancreatic $\beta$ cell function through the induction of oxidative stress," The Journal of Biological Chemistry, vol. 276, no. 33, pp. 3109931104, 2001.

[21] H. Kaneto, T.-A. Matsuoka, Y. Nakatani, et al., "Oxidative stress, ER stress, and the JNK pathway in type 2 diabetes," Journal of Molecular Medicine, vol. 83, no. 6, pp. 429-439, 2005.

[22] T.-A. Matsuoka, Y. Kajimoto, H. Watada, et al., "Glycationdependent, reactive oxygen species-mediated suppression of the insulin gene promoter activity in HIT cells," The Journal of Clinical Investigation, vol. 99, no. 1, pp. 144-150, 1997. 
[23] R. P. Robertson, J. Harmon, P. O. Tran, Y. Tanaka, and H. Takahashi, "Glucose toxicity in $\beta$-cells: type 2 diabetes, good radicals gone bad, and the glutathione connection," Diabetes, vol. 52, no. 3, pp. 581-587, 2003.

[24] A. P. Robertson, "Chronic oxidative stress as a central mechanism for glucose toxicity in pancreatic islet beta cells in diabetes," The Journal of Biological Chemistry, vol. 279, no. 41, pp. 42351-42354, 2004.

[25] Y. Tanaka, C. E. Gleason, P. O. T. Tran, J. S. Harmon, and R. P. Robertson, "Prevention of glucose toxicity in HIT-T15 cells and Zucker diabetic fatty rats by antioxidants," Proceedings of the National Academy of Sciences of the United States of America, vol. 96, pp. 10857-10862, 1999.

[26] Y. Tanaka, P. O. T. Tran, J. Harmon, and R. P. Robertson, "A role of glutathione peroxidase in protecting pancreatic $\beta$ cells against oxidative stress in a model of glucose toxicity," Proceedings of the National Academy of Sciences of the United States of America, vol. 99, pp. 12363-12368, 2002.

[27] K. Sakai, K. Matsumoto, T. Nishikawa, et al., "Mitochondrial reactive oxygen species reduce insulin secretion by pancreatic $\beta$-cells," Biochemical and Biophysical Research Communications, vol. 300, no. 1, pp. 216-222, 2003.

[28] H. Kaneto, J. Fujii, T. Myint, et al., "Reducing sugars trigger oxidative modification and apoptosis in pancreatic $\beta$-cells by provoking oxidative stress through the glycation reaction," Biochemical Journal, vol. 320, no. 3, pp. 855-863, 1996.

[29] H. Ohlsson, K. Karlsson, and T. Edlund, "IPF1, a homeodomain-containing transactivator of the insulin gene," EMBO Journal, vol. 12, no. 11, pp. 4251-4259, 1993.

[30] J. Leonard, B. Peers, T. Johnson, K. Ferreri, S. Lee, and M. R. Montminy, "Characterization of somatostatin transactivating factor-1, a novel homeobox factor that stimulates somatostatin expression in pancreatic islet cells," Molecular Endocrinology, vol. 7, no. 10, pp. 1275-1283, 1993.

[31] C. P. Miller, R. E. McGehee Jr., and J. F. Habener, "IDX1: a new homeodomain transcription factor expressed in rat pancreatic islets and duodenum that transactivates the somatostatin gene," EMBO Journal, vol. 13, no. 5, pp. 11451156, 1994.

[32] J. Jonsson, L. Carlsson, T. Edlund, and H. Edlund, "Insulinpromoter-factor 1 is required for pancreas development in mice," Nature, vol. 371, no. 6498, pp. 606-609, 1994.

[33] D. A. Stoffers, N. T. Zinkin, V. Stanojevic, W. L. Clarke, and J. F. Habener, "Pancreatic agenesis attributable to a single nucleotide deletion in the human IPF1 gene coding sequence," Nature Genetics, vol. 15, no. 1, pp. 106-110, 1997.

[34] U. Ahlgren, J. Jonsson, L. Jonsson, K. Simu, and H. Edlund, " $\beta$-cell-specific inactivation of the mouse Ipf1/Pdxl gene results in loss of the $\beta$-cell phenotype and maturity onset diabetes," Genes and Development, vol. 12, no. 12, pp. 17631768, 1998.

[35] S. Ferber, A. Halkin, H. Cohen, et al., "Pancreatic and duodenal homeobox gene 1 induces expression of insulin genes in liver and ameliorates streptozotocin-induced hyperglycemia," Nature Medicine, vol. 6, no. 5, pp. 568-572, 2000.

[36] A. M. Holland, M. A. Hale, H. Kagami, R. E. Hammer, and R. J. MacDonald, "Experimental control of pancreatic development and maintenance," Proceedings of the National Academy of Sciences of the United States of America, vol. 99, no. 19, pp. 12236-12241, 2002.

[37] H. Noguchi, H. Kaneto, G. C. Weir, and S. Bonner-Weir, "PDX-1 protein containing its own antennapedia-like pro- tein transduction domain can transduce pancreatic duct and islet cells," Diabetes, vol. 52, no. 7, pp. 1732-1737, 2003.

[38] S. Miyazaki, E. Yamato, and J.-I. Miyazaki, "Regulated expression of PDX-1 promotes in vitro differentiation of insulin-producing cells from embryonic stem cells," Diabetes, vol. 53, no. 4, pp. 1030-1037, 2004.

[39] H. Kaneto, Y. Nakatani, T. Miyatsuka, et al., "PDX-1/VP16 fusion protein, together with NeuroD or Ngn3, markedly induces insulin gene transcription and ameliorates glucose tolerance," Diabetes, vol. 54, no. 4, pp. 1009-1022, 2005.

[40] H. Kaneto, T. Miyatsuka, T. Shiraiwa, et al., "Crucial role of PDX-1 in pancreas development, $\beta$-cell differentiation, and induction of surrogate $\beta$-cells," Current Medicinal Chemistry, vol. 14, no. 16, pp. 1745-1752, 2007.

[41] H. Kaneto, T. Miyatsuka, D. Kawamori, et al., "PDX-1 and MafA play a crucial role in pancreatic $\beta$-cell differentiation and maintenance of mature $\beta$-cell function," Endocrine Journal, vol. 55, pp. 235-252, 2008.

[42] M. Olbrot, J. Rud, L. G. Moss, and A. Sharma, "Identification of $\beta$-cell-specific insulin gene transcription factor RIPE3b1 as mammalian MafA," Proceedings of the National Academy of Sciences of the United States of America, vol. 99, no. 10, pp. 6737-6742, 2002.

[43] K. Kataoka, S.-I. Han, S. Shioda, M. Hirai, M. Nishizawa, and H. Handa, "MafA is a glucose-regulated and pancreatic $\beta$-cell-specific transcriptional activator for the insulin gene," The Journal of Biological Chemistry, vol. 277, no. 51, pp. 49903-49910, 2002.

[44] T.-A. Matsuoka, L. Zhao, I. Artner, et al., "Members of the large Maf transcription family regulate insulin gene transcription in islet $\beta$ cells," Molecular and Cellular Biology, vol. 23, no. 17, pp. 6049-6062, 2003.

[45] T.-A. Matsuoka, I. Artner, E. Henderson, A. Means, M. Sander, and R. Stein, "The MafA transcription factor appears to be responsible for tissue-specific expression of insulin," Proceedings of the National Academy of Sciences of the United States of America, vol. 101, no. 9, pp. 2930-2933, 2004.

[46] H. Kaneto, T.-A. Matsuoka, Y. Nakatani, et al., "A crucial role of MafA as a novel therapeutic target for diabetes," The Journal of Biological Chemistry, vol. 280, no. 15, pp. 1504715052, 2005.

[47] T.-A. Matsuoka, H. Kaneto, R. Stein, et al., "MafA regulates expression of genes important to islet $\beta$-cell function," Molecular Endocrinology, vol. 21, no. 11, pp. 2764-2774, 2007.

[48] S. Lenzen, J. Drinkgern, and M. Tiedge, "Low antioxidant enzyme gene expression in pancreatic islets compared with various other mouse tissues," Free Radical Biology and Medicine, vol. 20, no. 3, pp. 463-466, 1996.

[49] M. Tiedge, S. Lortz, J. Drinkgern, and S. Lenzen, "Relation between antioxidant enzyme gene expression and antioxidative defense status of insulin-producing cells," Diabetes, vol. 46, no. 11, pp. 1733-1742, 1997.

[50] J. Shao, N. Iwashita, F. Ikeda, et al., "Beneficial effects of candesartan, an angiotensin II type 1 receptor blocker, on $\beta$ cell function and morphology in $\mathrm{db} / \mathrm{db}$ mice," Biochemical and Biophysical Research Communications, vol. 344, no. 4, pp. 1224-1233, 2006.

[51] M. Nakayama, T. Inoguchi, T. Sonta, et al., "Increased expression of $\mathrm{NAD}(\mathrm{P}) \mathrm{H}$ oxidase in islets of animal models of type 2 diabetes and its improvement by an AT1 receptor antagonist," Biochemical and Biophysical Research Communications, vol. 332, no. 4, pp. 927-933, 2005. 
[52] C. Carlsson, L. A. H. Borg, and N. Welsh, "Sodium palmitate induces partial mitochondrial uncoupling and reactive oxygen species in rat pancreatic islets in vitro," Endocrinology, vol. 140, no. 8, pp. 3422-3428, 1999.

[53] J. W. Joseph, V. Koshkin, M. C. Saleh, et al., "Free fatty acidinduced $\beta$-cell defects are dependent on uncoupling protein 2 expression," The Journal of Biological Chemistry, vol. 279, no. 49, pp. 51049-51056, 2004.

[54] X. Wang, H. Li, D. De Leo, et al., "Gene and protein kinase expression profiling of reactive oxygen species-associated lipotoxicity in the pancreatic $\beta$-cell line MIN6," Diabetes, vol. 53, pp. 129-140, 2004.

[55] A. I. Oprescu, G. Bikopoulos, A. Naassan, et al., "Free fatty acid-induced reduction in glucose-stimulated insulin secretion: evidence for a role of oxidative stress in vitro and in vivo," Diabetes, vol. 56, no. 12, pp. 2927-2937, 2007.

[56] G. Bikopoulos, A. da Silva Pimenta, S. C. Lee, et al., "Ex vivo transcriptional profiling of human pancreatic islets following chronic exposure to monounsaturated fatty acids," Journal of Endocrinology, vol. 196, no. 3, pp. 455-464, 2008.

[57] M. Shimabukuro, M. Ohneda, Y. Lee, and R. H. Unger, "Role of nitric oxide in obesity-induced $\beta$ cell disease," The Journal of Clinical Investigation, vol. 100, no. 2, pp. 290-295, 1997.

[58] H. Kaneto, J. Fujii, H. G. Seo, et al., "Apoptotic cell death triggered by nitric oxide in pancreatic $\beta$-cells," Diabetes, vol. 44, no. 7, pp. 733-738, 1995.

[59] H. Kaneto, G. Xu, N. Fujii, S. Kim, S. Bonner-Weir, and G. C. Weir, "Involvement of c-Jun N-terminal kinase in oxidative stress-mediated suppression of insulin gene expression," The Journal of Biological Chemistry, vol. 277, no. 33, pp. 3001030018, 2002.

[60] D. Kawamori, Y. Kajimoto, H. Kaneto, et al., "Oxidative stress induces nucleo-cytoplasmic translocation of pancreatic transcription factor PDX-1 through activation of c-Jun $\mathrm{NH}_{2}$ terminal kinase," Diabetes, vol. 52, no. 12, pp. 2896-2904, 2003.

[61] S. Ogg, S. Paradis, S. Gottlieb, et al., "The fork head transcription factor DAF-16 transduces insulin-like metabolic and longevity signals in C. elegans," Nature, vol. 389, no. 6654, pp. 994-999, 1997.

[62] D. Accili and K. C. Arden, "FoxOs at the crossroads of cellular metabolism, differentiation, and transformation," Cell, vol. 117, no. 4, pp. 421-426, 2004.

[63] J. Nakae, W. H. Biggs III, T. Kitamura, et al., "Regulation of insulin action and pancreatic $\beta$-cell function by mutated alleles of the gene encoding forkhead transcription factor Foxo1," Nature Genetics, vol. 32, no. 2, pp. 245-253, 2002.

[64] W. H. Biggs III, J. Meisenhelder, T. Hunter, W. K. Cavenee, and K. C. Arden, "Protein kinase B/Akt-mediated phosphorylation promotes nuclear exclusion of the winged helix transcription factor FKHR1," Proceedings of the National Academy of Sciences of the United States of America, vol. 96, no. 13, pp. 7421-7426, 1999.

[65] T. Kitamura, J. Nakae, Y. Kitamura, et al., "The forkhead transcription factor Foxo1 links insulin signaling to $P d x 1$ regulation of pancreatic $\beta$ cell growth," The Journal of Clinical Investigation, vol. 110, no. 12, pp. 1839-1847, 2002.

[66] D. Kawamori, H. Kaneto, Y. Nakatani, et al., "The forkhead transcription factor Foxol bridges the JNK pathway and the transcription factor PDX-1 through its intracellular translocation," The Journal of Biological Chemistry, vol. 281, no. 2, pp. 1091-1098, 2006.
[67] M. K. Lehtinen, Z. Yuan, P. R. Boag, et al., “A conserved MSTFOXO signaling pathway mediates oxidative-stress responses and extends life span," Cell, vol. 125, pp. 987-1001, 2006.

[68] C. Bonny, P. Nicod, and G. Waeber, "IB1, a JIP-1-related nuclear protein present in insulin-secreting cells," The Journal of Biological Chemistry, vol. 273, no. 4, pp. 1843-1846, 1998.

[69] M. Dickens, J. S. Rogers, J. Cavanagh, et al., "A cytoplasmic inhibitor of the JNK signal transduction pathway," Science, vol. 277, no. 5326, pp. 693-696, 1997.

[70] G. Waeber, J. Delplanque, C. Bonny, et al., "The gene MAPK8IP1, encoding islet-brain-1, is a candidate for type 2 diabetes," Nature Genetics, vol. 24, no. 3, pp. 291-295, 2000.

[71] G. I. Shulman, "Cellular mechanisms of insulin resistance," The Journal of Clinical Investigation, vol. 106, no. 2, pp. 171176, 2000.

[72] A. R. Saltiel and C. R. Kahn, "Insulin signalling and the regulation of glucose and lipid metabolism," Nature, vol. 414, no. 6865 , pp. 799-806, 2001.

[73] T. Kadowaki, "Insights into insulin resistance and type 2 diabetes from knockout mouse models," The Journal of Clinical Investigation, vol. 106, no. 4, pp. 459-465, 2000.

[74] B. B. Kahn and J. S. Flier, "Obesity and insulin resistance," The Journal of Clinical Investigation, vol. 106, no. 4, pp. 473$481,2000$.

[75] J. L. Evans, I. D. Goldfine, B. A. Maddux, and G. M. Grodsky, "Oxidative stress and stress-activated signaling pathways: a unifying hypothesis of type 2 diabetes," Endocrine Reviews, vol. 23, no. 5, pp. 599-622, 2002.

[76] A. Rudich, A. Tlrosh, R. Potashnik, R. Hemi, H. Kanety, and N. Bashan, "Prolonged oxidative stress impairs insulininduced GLUT4 translocation in 3T3-L1 adipocytes," Diabetes, vol. 47, no. 10, pp. 1562-1569, 1998.

[77] A. Tirosh, R. Potashnik, N. Bashan, and A. Rudich, "Oxidative stress disrupts insulin-induced cellular redistribution of insulin receptor substrate-1 and phosphatidylinositol 3kinase in 3T3-L1 adipocytes: a putative cellular mechanism for impaired protein kinase B activation and GLUT4 translocation," The Journal of Biological Chemistry, vol. 274, no. 15, pp. 10595-10602, 1999.

[78] C. A. Haber, T. K. T. Lam, Z. Yu, et al., "N-acetylcysteine and taurine prevent hyperglycemia-induced insulin resistance in vivo: possible role of oxidative stress," American Journal of Physiology, vol. 285, no. 4, pp. E744-E753, 2003.

[79] S. Jacob, P. Ruus, R. Hermann, et al., "Oral administration of rac- $\alpha$-lipoic acid modulates insulin sensitivity in patients with type-2 diabetes mellitus: a placebo-controlled pilot trial," Free Radical Biology and Medicine, vol. 27, no. 3-4, pp. 309-314, 1999.

[80] T. Konrad, P. Vicini, K. Kusterer, et al., “ $\alpha$-lipoic acid treatment decreases serum lactate and pyruvate concentrations and improves glucose effectiveness in lean and obese patients with type 2 diabetes," Diabetes Care, vol. 22, no. 2, pp. 280287, 1999.

[81] G. S. Hotamisligil, "Role of endoplasmic reticulum stress and c-Jun $\mathrm{NH}_{2}$-terminal kinase pathways in inflammation and origin of obesity and diabetes," Diabetes, vol. 54, supplement 2, pp. S73-S78, 2005.

[82] K. E. Wellen and G. S. Hotamisligil, "Inflammation, stress, and diabetes," The Journal of Clinical Investigation, vol. 115, no. 5, pp. 1111-1119, 2005. 
[83] J. Hirosumi, G. Tuncman, L. Chang, et al., "A central role for JNK in obesity and insulin resistance," Nature, vol. 420, no. 6913, pp. 333-336, 2002.

[84] Y. Nakatani, H. Kaneto, D. Kawamori, et al., "Modulation of the JNK pathway in liver affects insulin resistance status," The Journal of Biological Chemistry, vol. 279, no. 44, pp. 4580345809, 2004.

[85] V. Aguirre, T. Uchida, L. Yenush, R. Davis, and M. F. White, "The c-Jun $\mathrm{NH}_{2}$-terminal kinase promotes insulin resistance during association with insulin receptor substrate1 and phosphorylation of Ser ${ }^{307}$," The Journal of Biological Chemistry, vol. 275, no. 12, pp. 9047-9054, 2000.

[86] G. Elliott and P. O'Hare, "Intercellular trafficking and protein delivery by a herpesvirus structural protein," Cell, vol. 88 , no. 2, pp. 223-233, 1997.

[87] A. D. Frankel and C. O. Pabo, "Cellular uptake of the tat protein from human immunodeficiency virus," Cell, vol. 55, no. 6, pp. 1189-1193, 1988.

[88] H. Nagahara, A. M. Vocero-Akbani, E. L. Snyder, et al., "Transduction of full-length TAT fusion proteins into mammalian cells: TAT-p-27 $7^{\text {Kip1 }}$ induces cell migration," Nature Medicine, vol. 4, no. 12, pp. 1449-1452, 1998.

[89] H. Noguchi, M. Matsushita, T. Okitsu, et al., "A new cellpermeable peptide allows successful allogeneic islet transplantation in mice," Nature Medicine, vol. 10, no. 3, pp. 305309, 2004.

[90] J. B. Rothbard, S. Garlington, Q. Lin, et al., "Conjugation of arginine oligomers to cyclosporin A facilitates topical delivery and inhibition of inflammation," Nature Medicine, vol. 6, no. 11, pp. 1253-1257, 2000.

[91] S. R. Schwarze, A. Ho, A. Vocero-Akbani, and S. F. Dowdy, "In vivo protein transduction: delivery of a biologically active protein into the mouse," Science, vol. 285, no. 5433, pp. 15691572, 1999.

[92] C. Bonny, A. Oberson, S. Negri, C. Sause, and D. F. Schorderet, "Cell-permeable peptide inhibitors of JNK: novel blockers of $\beta$-cell death,” Diabetes, vol. 50, pp. 77-82, 2001.

[93] H. Kaneto, Y. Nakatani, T. Miyatsuka, et al., "Possible novel therapy for diabetes with cell-permeable JNK-inhibitory peptide," Nature Medicine, vol. 10, no. 10, pp. 1128-1132, 2004.

[94] F. Urano, X. Wang, A. Bertolotti, et al., "Coupling of stress in the ER to activation of JNK protein kinases by transmembrane protein kinase IRE1," Science, vol. 287, no. 5453, pp. 664-666, 2000.

[95] U. Ozcan, Q. Cao, E. Yilmaz, et al., "Endoplasmic reticulum stress links obesity, insulin action, and type 2 diabetes," Science, vol. 306, no. 5695, pp. 457-461, 2004.

[96] K. E. Wellen and G. S. Hotamisligil, "Inflammation, stress, and diabetes," The Journal of Clinical Investigation, vol. 115, no. 5, pp. 1111-1119, 2005.

[97] M. Yuan, N. Konstantopoulos, J. Lee, et al., "Reversal of obesity- and diet-induced insulin resistance with salicylates or targeted disruption of Ikk $\beta$," Science, vol. 293, no. 5535, pp. 1673-1677, 2001.

[98] D. Cai, M. Yuan, D. F. Frantz, et al., "Local and systemic insulin resistance resulting from hepatic activation of IKK$\beta$ and NF- $\kappa$ B," Nature Medicine, vol. 11, no. 2, pp. 183-190, 2005.

[99] M. C. Arkan, A. L. Hevener, F. R. Greten, et al., "IKK- $\beta$ links inflammation to obesity-induced insulin resistance," Nature Medicine, vol. 11, no. 2, pp. 191-198, 2005.
[100] Y. Tamura, T. Ogihara, T. Uchida, et al., "Amelioration of glucose tolerance by hepatic inhibition of nuclear factor $\kappa \mathrm{B}$ in db/db mice," Diabetologia, vol. 50, no. 1, pp. 131-141, 2007.

[101] R. Kawamori, Y. Yamasaki, H. Matsushima, et al., "Prevalence of carotid atherosclerosis in diabetic patients: ultrasound high-resolution B-mode imaging on carotid arteries," Diabetes Care, vol. 15, no. 10, pp. 1290-1294, 1992.

[102] Y. Yamasaki, R. Kawamori, H. Matsushima, et al., "Atherosclerosis in carotid artery of young IDDM patients monitored by ultrasound high-resolution B-mode imaging," Diabetes, vol. 43, no. 5, pp. 634-639, 1994.

[103] Y. Yamasaki, R. Kawamori, H. Matsushima, et al., "Asymptomatic hyperglycaemia is associated with increased intimal plus medial thickness of the carotid artery," Diabetologia, vol. 38, no. 5, pp. 585-591, 1995.

[104] K. Aral, Y. Yamasaki, Y. Kajimoto, et al., "Association of methylenetetrahydrofolate reductase gene polymorphism with carotid arterial wall thickening and myocardial infarction risk in NIDDM," Diabetes, vol. 46, no. 12, pp. 21022104, 1997.

[105] R. Hayaishi-Okano, Y. Yamasaki, Y. Kajimoto, et al., "Association of $\mathrm{NAD}(\mathrm{P}) \mathrm{H}$ oxidase $p 22$ phox gene variation with advanced carotid atherosclerosis in Japanese type 2 diabetes," Diabetes Care, vol. 26, no. 2, pp. 458-463, 2003.

[106] Y. Yamasaki, N. Katakami, K. Sakamoto, et al., "Combination of multiple genetic risk factors was synergistically associated with carotid atherosclerosis in subjects with type 2 diabetes," Diabetes Care, vol. 29, pp. 2445-2451, 2006.

[107] N. Katakami, Y. Yamasaki, R. Hayaishi-Okano, et al., "Metformin or gliclazide, rather than glibenclamide, attenuate progression of carotid intima-media thickness in subjects with type 2 diabetes," Diabetologia, vol. 47, no. 11, pp. 19061913, 2004.

[108] Y. Yamasaki, N. Katakami, R. Hayaishi-Okano, et al., “ $\alpha$ glucosidase inhibitor reduces the progression of carotid intima-media thickness," Diabetes Research and Clinical Practice, vol. 67, no. 3, pp. 204-210, 2005.

[109] H. Yokoyama, N. Katakami, and Y. Yamasaki, "Recent advances of intervention to inhibit progression of carotid intima-media thickness in patients with type 2 diabetes mellitus," Stroke, vol. 37, no. 9, pp. 2420-2427, 2006.

[110] M. Ushio-Fukai, A. M. Zafari, T. Fukui, N. Ishizaka, and K. K. Griendling, "p22phox is a critical component of the superoxide-generating NADH/NADPH oxidase system and regulates angiotensin II-induced hypertrophy in vascular smooth muscle cells," The Journal of Biological Chemistry, vol. 271, no. 38, pp. 23317-23321, 1996.

[111] U. Hink, H. Li, H. Mollnau, et al., "Mechanisms underlying endothelial dysfunction in diabetes mellitus," Circulation Research, vol. 88, no. 2, pp. E14-E22, 2001.

[112] T. Inoguchi, P. Li, F. Umeda, et al., "High glucose level and free fatty acid stimulate reactive oxygen species production through protein kinase $\mathrm{C}$-dependent activation of $\mathrm{NAD}(\mathrm{P}) \mathrm{H}$ oxidase in cultured vascular cells," Diabetes, vol. 49, no. 11, pp. 1939-1945, 2000.

[113] T. J. Guzik, S. Mussa, D. Gastaldi, et al., "Mechanisms of increased vascular superoxide production in human diabetes mellitus: role of $\mathrm{NAD}(\mathrm{P}) \mathrm{H}$ oxidase and endothelial nitric oxide synthase," Circulation, vol. 105, no. 14, pp. 1656-1662, 2002.

[114] Y. K. Kim, M.-S. Lee, S. M. Son, et al., "Vascular NADH oxidase is involved in impaired endothelium-dependent 
vasodilation in OLETF rats, a model of type 2 diabetes," Diabetes, vol. 51, no. 2, pp. 522-527, 2002.

[115] P. A. Barry-Lane, C. Patterson, M. van der Merwe, et al., "p47phox is required for atherosclerotic lesion progression in A poE ${ }^{-/-}$mice," The Journal of Clinical Investigation, vol. 108, no. 10, pp. 1513-1522, 2001.

[116] H. Azumi, N. Inoue, Y. Ohashi, et al., "Superoxide generation in directional coronary atherectomy specimens of patients with angina pectoris: important role of $\mathrm{NAD}(\mathrm{P}) \mathrm{H}$ oxidase," Arteriosclerosis, Thrombosis, and Vascular Biology, vol. 22, no. 11, pp. 1838-1844, 2002.

[117] A. Fortuno, G. San Jose, M. U. Moreno, O. Beloqui, J. Diez, and G. Zalba, "Phagocytic NADPH oxidase overactivity underlies oxidative stress in metabolic syndrome," Diabetes, vol. 55, pp. 209-215, 2006.

[118] N. Katakami, K. Sakamoto, H. Kaneto, et al., "Combined effect of oxidative stress-related gene polymorphisms on atherosclerosis," Biochemical and Biophysical Research Communications, vol. 379, pp. 861-865, 2009.

[119] N. Katakami, M. Saito, H. Kaneto, et al., "Combined effect of oxidative stress-related gene polymorphisms on the progression of carotid atherosclerosis in Japanese type 2 diabetes," Atherosclerosis, vol. 207, no. 1, pp. 29-31, 2009.

[120] N. Katakami, K. Sakamoto, H. Kaneto, et al., "Cumulative effect of oxidative stress-related gene polymorphisms on myocardial infarction in type 2 diabetes," Diabetes Care, vol. 32, no. 5, article e55, 2009.

[121] H. Cai and D. G. Harrison, "Endothelial dysfunction in cardiovascular diseases: the role of oxidant stress," Circulation Research, vol. 87, no. 10, pp. 840-844, 2000.

[122] J. L. Mehta, N. Rasouli, A. K. Sinha, and B. Molavi, “Oxidative stress in diabetes: a mechanistic overview of its effects on atherogenesis and myocardial dysfunction," International Journal of Biochemistry and Cell Biology, vol. 38, no. 5-6, pp. 794-803, 2006.

[123] U. Chakravarthy, R. G. Hayes, A. W. Stitt, E. McAuley, and D. B. Archer, "Constitutive nitric oxide synthase expression in retinal vascular endothelial cells is suppressed by high glucose and advanced glycation end products," Diabetes, vol. 47, no. 6, pp. 945-952, 1998.

[124] N. R. Madamanchi, A. Vendrov, and M. S. Runge, "Oxidative stress and vascular disease," Arteriosclerosis, Thrombosis, and Vascular Biology, vol. 25, no. 1, pp. 29-38, 2005.

[125] P. Delafontaine and L. Ku, "Reactive oxygen species stimulate insulin-like growth factor I synthesis in vascular smooth muscle cells," Cardiovascular Research, vol. 33, no. 1, pp. 216222, 1997.

[126] N. G. Stephens, A. Parsons, P. M. Schofield, F. Kelly, K. Cheeseman, and M. J. Mitchinson, "Randomised controlled trial of vitamin $\mathrm{E}$ in patients with coronary disease: Cambridge Heart Antioxidant Study (CHAOS)," The Lancet, vol. 347, no. 9004, pp. 781-786, 1996.

[127] J.-C. Tardif, G. Côté, J. Lespérance, et al., "Probucol and multivitamins in the prevention of restenosis after coronary angioplasty. Multivitamins and Probucol Study Group," The New England Journal of Medicine, vol. 337, no. 6, pp. 365-372, 1997.

[128] M. Yoshizumi, J.-I. Abe, J. Haendeler, Q. Huang, and B. C. Berk, "Src and Cas mediate JNK activation but not ERK1/2 and p38 kinases by reactive oxygen species," The Journal of Biological Chemistry, vol. 275, no. 16, pp. 11706-11712, 2000.
[129] Y. Hu, L. Cheng, B.-W. Hochleitner, and Q. Xu, "Activation of mitogen-activated protein kinases (ERK/JNK) and AP1 transcription factor in rat carotid arteries after balloon injury," Arteriosclerosis, Thrombosis, and Vascular Biology, vol. 17, no. 11, pp. 2808-2816, 1997.

[130] S. Kim, Y. Izumi, M. Yano, et al., "Angiotensin blockade inhibits activation of mitogen-activated protein kinases in rat balloon-injured artery," Circulation, vol. 97, no. 17, pp. 17311737, 1998.

[131] H. Koyama, N. E. Olson, F. F. Dastvan, and M. A. Reidy, "Cell replication in the arterial wall: activation of signaling pathway following in vivo injury," Circulation Research, vol. 82, no. 6, pp. 713-721, 1998.

[132] Y. Izumi, S. Kim, M. Namba, et al., "Gene transfer of dominant-negative mutants of extracellular signal-regulated kinase and $\mathrm{c}$-Jun $\mathrm{NH}_{2}$-terminal kinase prevents neointimal formation in balloon-injured rat artery," Circulation Research, vol. 88, no. 11, pp. 1120-1126, 2001.

[133] R. Ricci, G. Sumara, I. Sumara, et al., "Requirement of JNK2 for scavenger receptor A-mediated foam cell formation in atherogenesis," Science, vol. 306, no. 5701, pp. 1558-1561, 2004.

[134] K. Yoshimura, H. Aoki, Y. Ikeda, et al., "Regression of abdominal aortic aneurysm by inhibition of c-Jun Nterminal kinase," Nature Medicine, vol. 11, no. 12, pp. 13301338, 2005.

[135] N. Katakami, H. Kaneto, H. Hao, et al., "Role of pim-1 in smooth muscle cell proliferation," The Journal of Biological Chemistry, vol. 279, no. 52, pp. 54742-54749, 2004.

[136] R. Amaravadi and C. B. Thompson, "The survival kinases Akt and Pim as potential pharmacological targets," The Journal of Clinical Investigation, vol. 115, no. 10, pp. 26182624, 2005. 


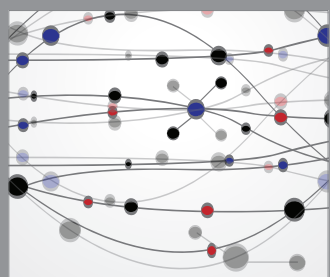

The Scientific World Journal
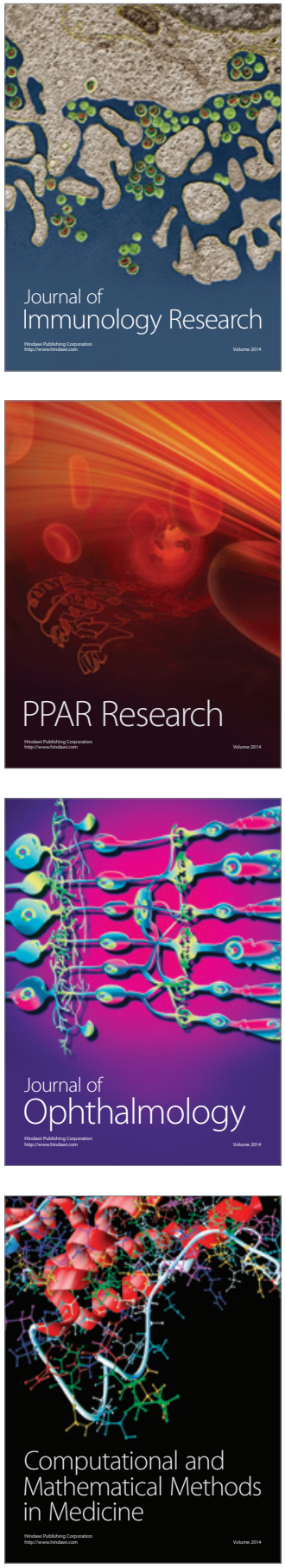

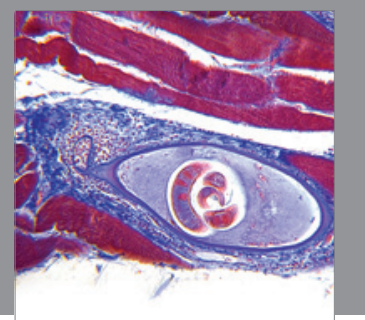

Gastroenterology

Research and Practice
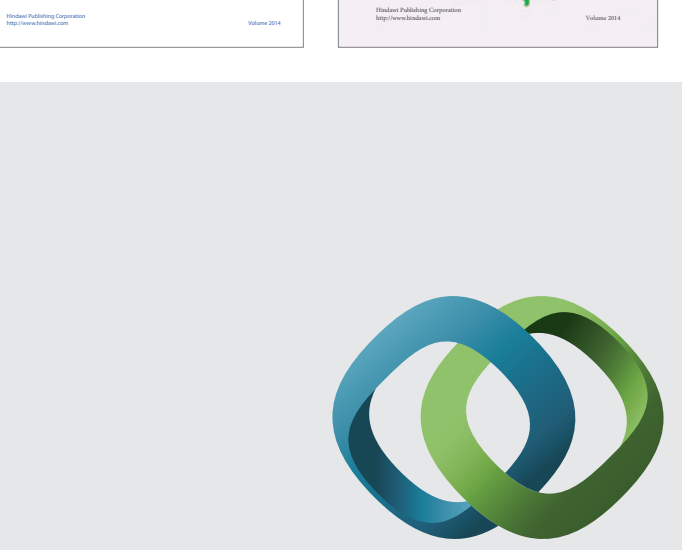

\section{Hindawi}

Submit your manuscripts at

http://www.hindawi.com
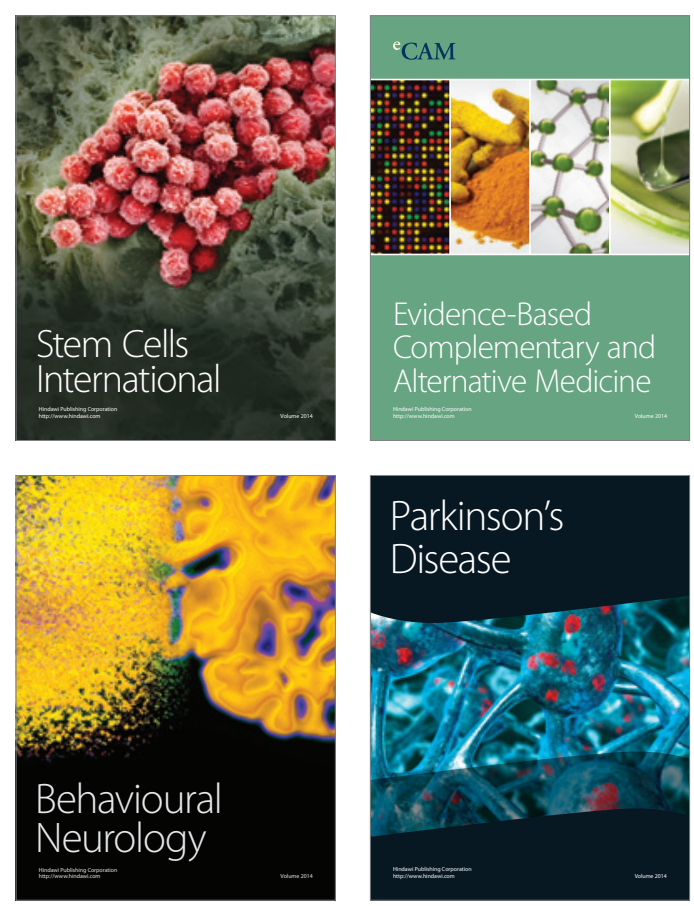

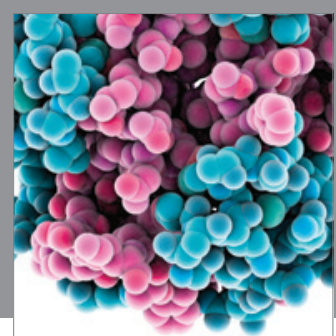

Journal of
Diabetes Research

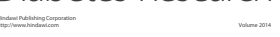

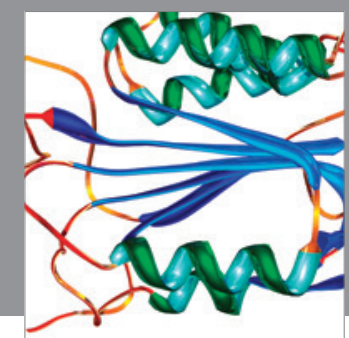

Disease Markers
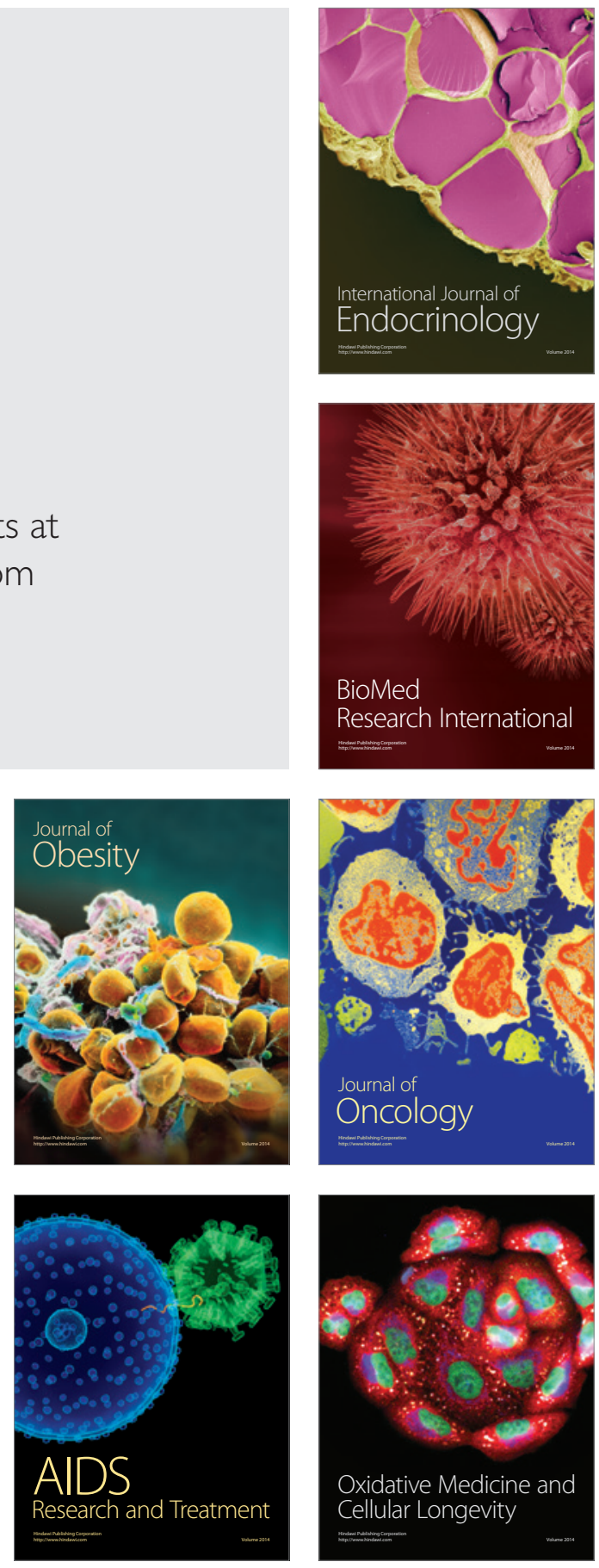